Article

\title{
Improving the Dyeability and Anti-Wrinkle Properties of Cotton Fabric via Oxidized Raffinose
}

\author{
Jiangfei Lou ${ }^{1}$, Jinfang Zhang ${ }^{2}$, Dan Wang ${ }^{1}$ and Xuerong Fan ${ }^{1, *}$ \\ 1 Key Laboratory of Science and Technology of Eco-Textile, Ministry of Education, Jiangnan University, \\ Wuxi 214122, China; jiangfeilou@stu.jiangnan.edu.cn (J.L.); 7190707009@stu.jiangnan.edu.cn (D.W.) \\ 2 Zhejiang Haoyu Science and Technology Co. Ltd., Hangzhou 312300, China; jinfang@zhejianghaoyu.com \\ * Correspondence: 8093200024@jiangnan.edu.cn
}

Citation: Lou, J.; Zhang, J.; Wang, D.; Fan, X. Improving the Dyeability and Anti-Wrinkle Properties of Cotton Fabric via Oxidized Raffinose. Appl. Sci. 2021, 11, 4641. https://doi.org/ 10.3390/app11104641

Academic Editor: Rocco Furferi

Received: 16 April 2021

Accepted: 15 May 2021

Published: 19 May 2021

Publisher's Note: MDPI stays neutral with regard to jurisdictional claims in published maps and institutional affiliations.

Copyright: (c) 2021 by the authors. Licensee MDPI, Basel, Switzerland. This article is an open access article distributed under the terms and conditions of the Creative Commons Attribution (CC BY) license (https:// creativecommons.org/licenses/by/ $4.0 /)$.

\begin{abstract}
In the anti-wrinkle finishing of cotton fabrics, the decreased dyeability of the finished fabrics has always been a difficult problem. A new anti-wrinkle finishing mode was developed to solve this problem by changing the finishing sequence of fabric dyeing and anti-wrinkle. In this research, the partial oxidization of raffinose with sodium periodate generated multiple aldehydes, which acted as multifunctional cross-linkers and endowed cotton fabrics with anti-wrinkle and hydrophilic properties. The structural characteristics of oxyRa were analyzed by FTIR and ${ }^{13} \mathrm{C}-\mathrm{NMR}$. Through response surface methodology (RSM), the finishing model of oxyRa was established from the influencing factors of catalyst concentration, $\mathrm{pH}$, curing temperature and time, and the optimized finishing process: the catalyst concentration was $20.12 \mathrm{~g} / \mathrm{L}, \mathrm{pH}$ was 4.32 , curing temperature was $150{ }^{\circ} \mathrm{C}$ and curing time was $120 \mathrm{~s}$. Under this condition, the predicted wrinkle recovery angle (WRA) of the finished fabric was up to $249.76^{\circ}$, Tensile strength (TS) was $75.62 \%$, Whiteness index (WI) was 70.69. Importantly, comparing the anti-wrinkle and dyeing performance of the fabric with anti-wrinkle and then dyeing and anti-wrinkle after dyeing, the oxyRa-treated fabrics showed better dyeing properties compared with previously reported dimethyldihydroxyethylene urea (DMDHEU), glutaraldehyde (GA), and 1,2,3,4-butanetetracarboxylic acid (BTCA). Analysis of the combined mechanism of different finishing agents and cellulose, demonstrated the reason why oxyRa can be used to change the order of dyeing and anti-wrinkle finishing.
\end{abstract}

Keywords: oxidized raffinose; polyaldehyde derivatives; anti-wrinkle finishing; dyeing; RSM; cotton fabric

\section{Introduction}

Cotton fabric has become one of the most widely used textile materials because of its wear comfort, hygroscopicity, breathability and softness [1,2]. Nevertheless, cotton fabrics readily form creases during home laundering which is undesirable for users. Because there are not enough covalent bonds in the cellulose chains, the original H-bonds in cotton cellulose will break and new $\mathrm{H}$-bonds form under friction, resulting in cotton fabric having poor anti-wrinkle properties $[1,3,4]$. In order to meet the application and use requirements of cotton fabrics, chemical cross-linking finishing agents must be applied as anti-wrinkle finishing for cotton fabrics.

In the chemical crosslinking anti-wrinkle finishing method of cotton fabrics, cotton fabrics are given excellent anti-wrinkle properties mainly through the etherification crosslinking of aldehyde groups and the esterification crosslinking of polycarboxylic acids. The etherification crosslinking of aldehyde groups is mainly represented by dimethylol dihydroxyethylene urea (DMDHEU) and glutaraldehyde (GA) [3,5]. The esterification crosslinking of polycarboxylic acid is mainly represented by 1,2,3,4-butanetetracarboxylic acid (BTCA) [6-8]. The reaction between cotton and crosslinker in anti-wrinkle finishing is a kind of complex multiphase reaction. The aldehyde and carboxylic groups of those agents form ether bonds by combining with the hydroxyl groups of cellulose to give 
cotton fabric anti-wrinkle properties. In the finishing process, the micro-pore size and internal surface area of the fiber are reduced, resulting in a decrease of the hydrophilicity and dyeability [9-11]. Therefore, anti-wrinkle finishing is usually carried out after dyeing or printing. In order to adapt to the trend of the clothing market toward small batch and multi-variety development, it is required that the dyeing process can be carried out after anti-wrinkle finishing. Therefore, it is necessary to develop a new type of antiwrinkle finishing agent, which can greatly improve the hydrophilicity and dyeability of the finished fabric.

Raffinose is the most well-known trisaccharide in Nature, being widely found in natural plants and in many vegetables (cabbage, cauliflower, potato, beet, onions, etc.), fruits (grapes, bananas, kiwi, etc.), rice (wheat, rice, oats, etc.). The seeds of some oil crops (soybeans, sunflower seeds, cottonseeds, peanuts, etc.) also contain varying amounts of raffinose. Raffinose is composed of galactose, fructose and glucose. To our knowledge, sodium periodate selectively cleaves the vicinal hydroxyls in carbohydrates to yield aldehyde groups [5,12-15]. The aldehyde group can be used as the reactive group to combine with the hydroxyl groups of cellulose to achieve anti-wrinkle properties. At the same time, the hydroxyl group of raffinose is introduced into the fiber as the reaction progresses to improve the hydrophilicity and dyeability of the finished fabric. Based on this mechanism, we have established the idea of changing the sequence of anti-wrinkle and dyeing finishing.

In this study, raffinose was partially oxidized by sodium periodate to obtain oxyraffinose (oxyRa), which was applied as an anti-crease finish for cotton fabric. The aldehyde content of oxyRa was titrated with hydroxylamine hydrochloride, and the structural characteristics were analyzed by FTIR and ${ }^{13} \mathrm{C}-\mathrm{NMR}$. The optimized finishing process was established through response surface methodology (RSM), the four influencing factors being catalyst concentration, $\mathrm{pH}$, curing temperature and time. Furthermore, we compared the anti-wrinkle and dyeability of cotton fabric treated with oxyRa, DMDHEU, glutaraldehyde and BTCA, and studied the combined mechanism of different cross-linking agents and cellulose to analyze the reasons for the different dyeing properties.

\section{Materials and Methods}

\subsection{Materials}

Cotton cloth (100\%) with 155 warp yarns per $2.54 \mathrm{~cm}$ warp and 79 wefts per $2.54 \mathrm{~cm}$ weft, weighing $113 \mathrm{~g} / \mathrm{m}^{2}$, was desized, scoured by the supplier (Shandong Ruyi Group Co., Ltd., Jining, China). Raffinose $5 \mathrm{H}_{2} \mathrm{O}$ (Ra), hydroxylamine hydrochloride, magnesium chloride, sodium hypophosphite monohydrate, and sodium hydroxide were purchased from Sinopharm Chemical Reagent Co., Ltd. (Shanghai, China). Sodium periodate was purchased from Shanghai Mclean Biochemical Technology Co. Ltd. (Shanghai, China). Three crosslinking agents-glutaraldehyde (25\% solution, Sinopharm Chemical Reagent Co. Ltd., Shanghai, China), DMDHEU (Dymatic Chemical Reagent Co. Ltd., Guangzhou, China), and BTCA (J\&K Scientific Ltd., Beijing, China) — were used. All chemicals were of reagent grade and used without further purification.

\subsection{Methods}

\subsubsection{Preparation of the oxyRa}

Periodate oxidation of raffinose was carried out according to a literature procedure with slight modifications [5,13]. In brief, raffinose $(17.83 \mathrm{~g}, 0.03 \mathrm{~mol})$ was dissolved in $300 \mathrm{~mL}$ of water and $\mathrm{NaIO}_{4}(32.0 \mathrm{~g}, 0.15 \mathrm{~mol})$ was added. After the reaction mixture was stirred in dark at $20^{\circ} \mathrm{C}$ for $24 \mathrm{~h}$, barium dichloride (18.32 g) was added and the entire mixture was stirred at $10{ }^{\circ} \mathrm{C}$ for $24 \mathrm{~h}$ to allow complete precipitation. The mixture was filtered, and the liquor containing the polyaldehyde derivative was obtained. The resulting solution was kept in a deep freezer at $-20{ }^{\circ} \mathrm{C}$ and then dried by lyophilization to obtain oxyRa powder. 


\subsubsection{Aldehyde Content}

Estimation of aldehyde content was performed by chemical titration. OxyRa $(0.1 \mathrm{~g})$ was dissolved in $25 \mathrm{~mL}$ of $0.25 \mathrm{~N}$ hydroxylamine hydrochloride solution and two drops of methyl orange indicator ( $0.05 \%$ solution) were added. The solution was allowed to stand for $2.0 \mathrm{~h}$ and then titrated with a $0.1 \mathrm{~N}$ sodium hydroxide solution until the solution turned from red to yellow. Taking the volume of sodium hydroxide solution consumed as the $\mathrm{x}$-coordinate and the $\mathrm{pH}$ value as the $\mathrm{y}$-coordinate, a curve with one folding points was obtained. The folding point was $\Delta V(\mathrm{~mL})$ of $\mathrm{NaOH}$. The aldehyde group content (mmol $\mathrm{C}=\mathrm{OH} / \mathrm{g}$ oxyRa) was calculated using Equation (1):

$$
\mathrm{B}=\frac{\Delta V \times 0.001 \times n_{\mathrm{NaOH}}}{w}
$$

where $\Delta V$ is the volume of $\mathrm{NaOH}$ consumed $(\mathrm{mL}), n_{\mathrm{NaOH}}$ is the concentration of $\mathrm{NaOH}$ $(\mathrm{mol} / \mathrm{L}), w$ is the dry sample weight.

\subsubsection{FTIR Analysis}

Fourier transform infrared spectroscopic analysis of raffinose (Ra) and oxyRaffinose (oxyRa) was carried out using an IRaffinity-1S instrument (Shimadzu. Suzhou, China) using the $\mathrm{KBr}$ pellet method with 32 scans for each sample at a resolution of $4 \mathrm{~cm}^{-1}$ in the scanning range of $4000-400 \mathrm{~cm}^{-1}$.

\subsubsection{C NMR Analysis}

The chemical structures of Ra and oxyRa were confirmed by ${ }^{13} \mathrm{C}-\mathrm{NMR}$ recorded on a AM-400 spectrometer (Bruker, Beijing, China). The samples $(0.05 \mathrm{~g})$ were dissolved in $0.5 \mathrm{~mL}$ of deuterated water $\left(\mathrm{D}_{2} \mathrm{O}\right)$.

\subsubsection{Anti-crease Treatment of Cotton Fabric}

The fabric sample was first immersed in an aqueous solution containing either oxyRa or DMDHEU, or glutaraldehyde, or BTCA with other auxiliary reagents and then padded with two dips and two nips using a two-bowl horizontal laboratory padder (Aaliruo, Guangzhou, China) to attain a wet pickup of $90 \%$. Impregnated fabrics were dried and then cured under specific conditions in a curing oven manufactured by Rapid Precion Machinery Co. Ltd. (Xiameng, China).

\subsubsection{Properties of Treated Fabrics}

Before the measurement, the samples were conditioned at $25 \pm 1{ }^{\circ} \mathrm{C}$ for $4 \mathrm{~h}$ under conditions of relative humidity $65 \pm 2 \%$. Wrinkle recovery angle was measured on an SDL Atlas M003A tester (Guangzhou, China) according to AATCC Testing Method 66-2003. Each sample was measured 5 times in the weft (f) and warp (w), and the average value of each group was taken.

Tensile strength was determined by an electronic fabric strength tester in accordance with ASTM Testing Method D-1424-1996, and tensile strength retention rate was calculated using an untreated cotton fabric as a control:

$$
T S=\frac{T_{t}}{T_{u}} * 100 \%
$$

where $T_{t}$ is the tensile strength $(\mathrm{cN})$ after treatment and $T_{u}$ is the tensile strength $(\mathrm{cN})$ before treatment. All mechanical properties were measured five times in the warp and weft directions.

Whiteness index (WI) of the treated fabrics were determined by AATCC Test Method 110-2005. A Datacolor $650^{\circledR}$ Bench top spectrophotometer (Suzhou, China) was used to test four different positions, calculating the average of every sample. 


\subsubsection{Dyeing}

In order to evaluate differences in hydrophilicity of anti-wrinkle finished fabrics, the fabrics and fabrics with anti-wrinkle finishing were dyed by C. I. Reactive Brilliant Red EC-3GL (Dichloro-s-triazine dye) at $60^{\circ} \mathrm{C}$ for $90 \mathrm{~min}$, sodium sulfate and sodium carbonate need to be added during the dyeing process. The $K / S$ (color strength) and $\Delta \mathrm{E}$ of the dyed fabrics were measured by ASTM D2244-16 (Standard practice for Calculation of Color Tolerances and Color Differences from Instrumentally Measured Color Coordinates).

\section{Results and Discussion}

\subsection{Partial Oxidization of Raffinose by Sodium Periodate}

In the present work, oxidation of raffinose were carried out using the 1:1, 1:2, 1:3, 1:4 and 1:5 molar ratio of raffinose to sodium periodate, which effectively cleaves glycols to more than two aldehyde groups (Scheme 1). In Scheme $1 \mathrm{~b}$, if vicinal diols in the raffinose molecule are partially cleaved by periodate oxidization without causing molecular fragmentation, the oxidized raffinose derivative contains multiple aldehyde groups $[11,13,15,16]$. Structurally, oxyRa was a formaldehyde-free anti-wrinkle finishing agents, and the polyaldehyde raffinose derivatives containing multiple aldehyde groups.

(a) Oxidation of diols to dialdehyde with sodium periodate.

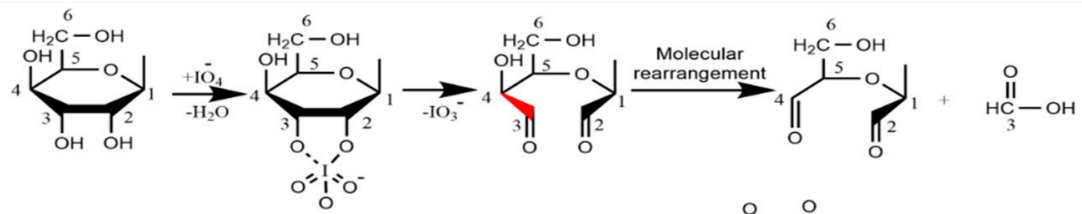

(b) Schematic of periodate oxidation of raffinose.
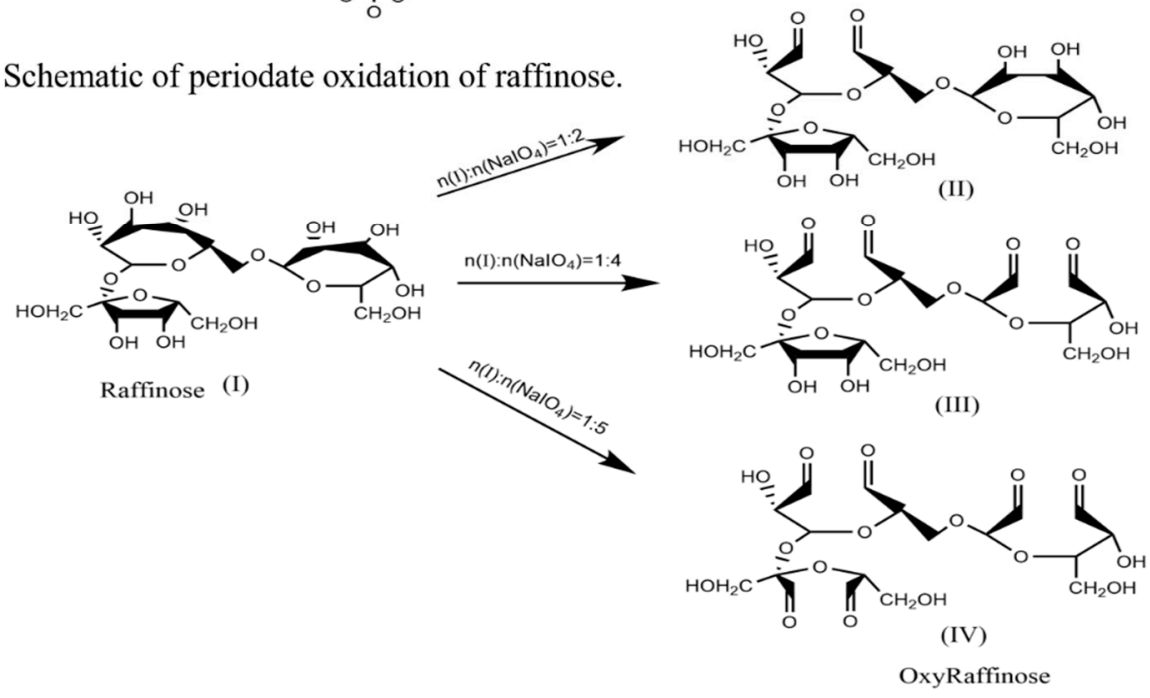

Scheme 1. Oxidation mechanism of sodium periodate.

The aldehyde content obtained with different molar ratios of raffinose to $\mathrm{NaIO}_{4}$ was measured using the hydroxylamine hydrochloride method, and the results are shown in Figure 1. It can be seen that the $\mathrm{NaIO}_{4}$ concentration had a strong influence on the aldehyde content of oxyRa. When the molar ratio of $\mathrm{Ra}$ to $\mathrm{NaIO}_{4}$ was 1:4, the aldehyde content was the highest after $24 \mathrm{~h}$ reaction time. This may be because the molecule of raffinose contains two glucose 6-membered rings and one fructose 5-membered rings, according to the literature, one part of the glucose ring requires two parts of $\mathrm{NaIO}_{4}$ to completely oxidize (open the ring to form a dialdehyde group) and one part of the fructose ring requires one part of $\mathrm{NaIO}_{4}$ to completely oxidized $[13,17,18]$. In the oxidation process, the glucose ring was easily oxidized by sodium periodate, and the ring-opening reaction occurs, and the reaction was faster. Although the fructose ring consumes a small amount of $\mathrm{NaIO}_{4}$, it was more difficult to be oxidized than the glucose ring. Then, the selection of the molar ratio was considering at 1:4. 


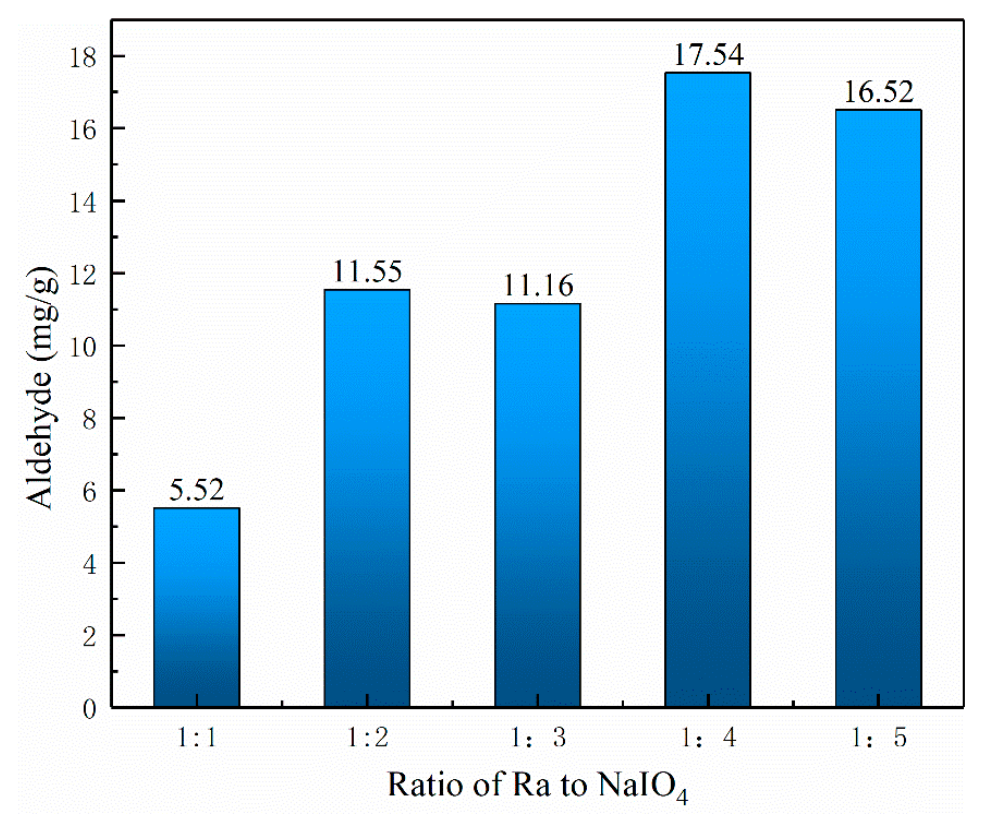

Figure 1. Aldehyde content of the oxyRa with difference ratio of $\mathrm{NaIO}_{4}$.

\subsection{Structure Analysis of oxyRa}

The various functional groups in the compounds have different characteristic absorption peaks when irradiated in the infrared spectrometer. The Ra and the oxyRa were scanned at $4000-400 \mathrm{~cm}^{-1}$ by Fourier transform infrared spectroscopy, and the characteristic absorption spectra are shown in Figure 2.

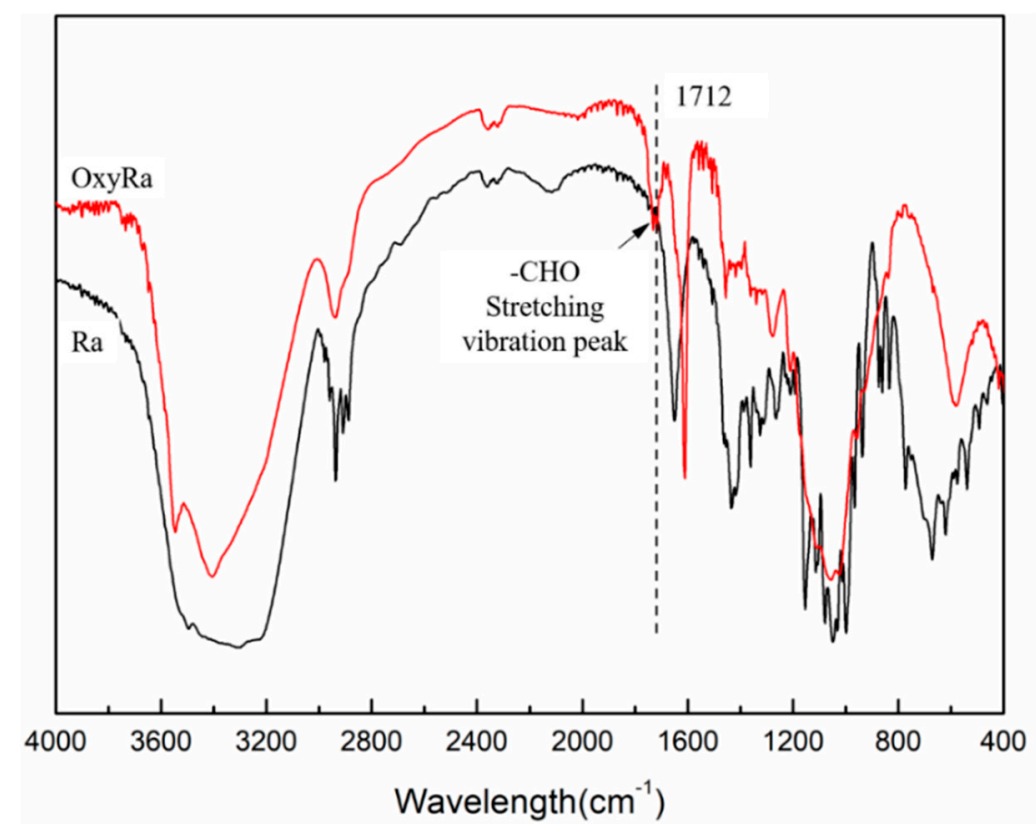

Figure 2. FTIR spectrum of Ra and oxyRa.

By analyzing its characteristic absorption peaks in Figure 2, the change of functional groups before and after oxidization of Ra can be known. The intensity of the oxyRa peaks at 2937 and $2914 \mathrm{~cm}^{-1}$ significantly weakened, proving that the position of $-\mathrm{CH}_{2}$ changed during the reaction and removal of $-\mathrm{CH}_{2}$ may also occurred to form formic acid [Scheme 1a]. The typical C=O stretching peak of oxyRa occurs at $1712 \mathrm{~cm}^{-1}$, while Ra has no absorption peak at this wavenumber which indicates that there were no aldehyde groups in the molecule. The 925 and $800 \mathrm{~cm}^{-1}$ peaks were the asymmetric stretching 
vibration peaks of pyran rings, and the peak of oxyRa obviously disappeared. This proved that the glucose ring undergoes a ring opening reaction during oxidation.

From previous studies, we expected oxyRa to be a mixture of isomers and hemiacetals. The structural ${ }^{13} \mathrm{C}$-NMR analysis results of one of the hemiacetal derivatives and raffinose was shown in Figure 3.

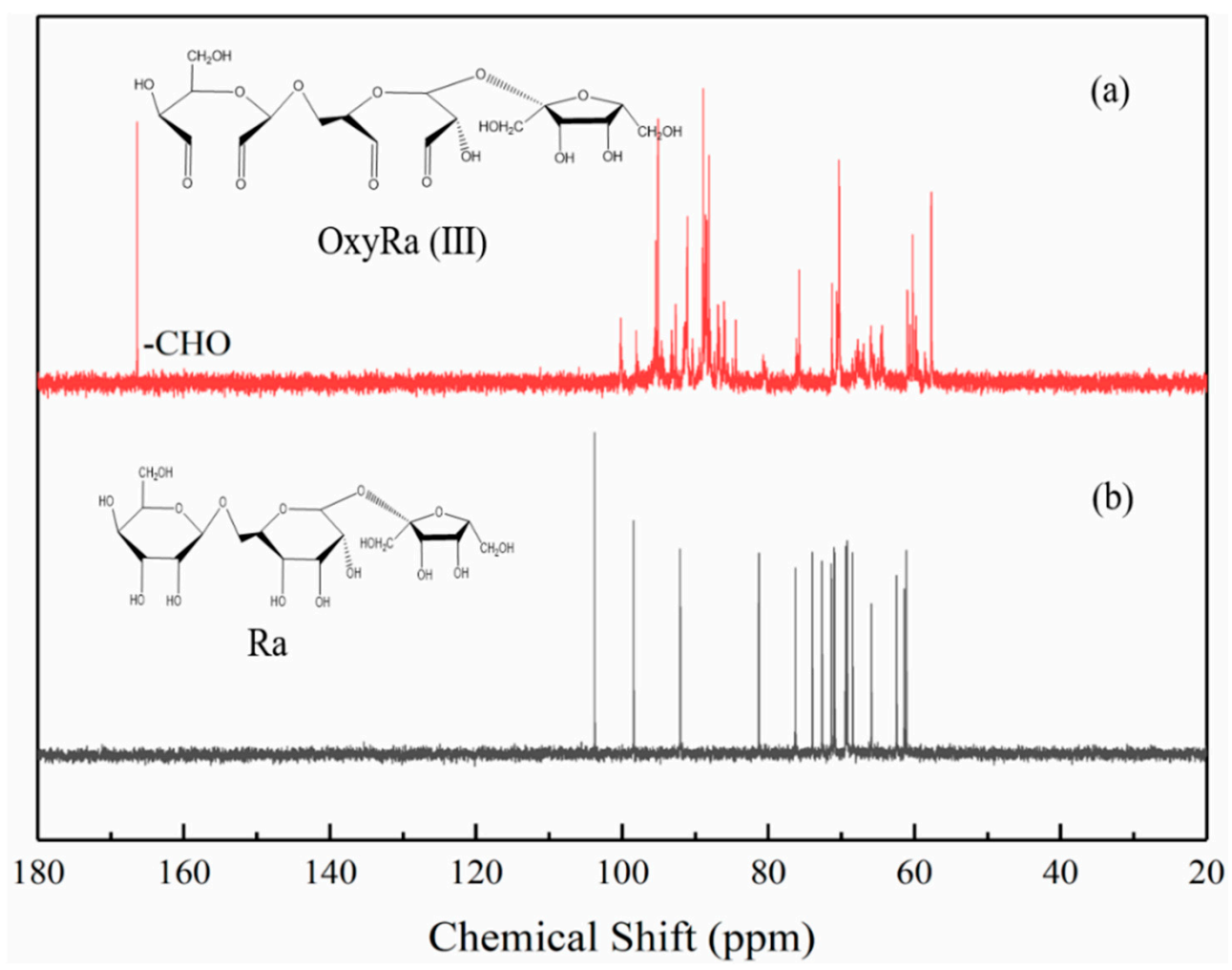

Figure $3 .{ }^{13} \mathrm{C}-\mathrm{NMR}$ spectrum of Ra and oxyRa. ((a) is oxyRa, (b) is Ra).

Comparative analysis of the ${ }^{13} \mathrm{C}-\mathrm{NMR}$ spectra of Ra and oxyRa in Figure 3 confirms that hemiacetal structures were indeed present in the oxyRa molecules. Figure $3 \mathrm{a}$ is the nuclear magnetic resonance spectrum of Ra, which exhibits an asymmetrical trisaccharide structure. The integral of the peak at $168 \mathrm{ppm}$ fits well with the structure characterized by a free - $\mathrm{CHO}$ group, as shown in Figure $3 \mathrm{~b}$. This also demonstrates that Ra was successfully oxidized to the desired polyaldehyde derivative using five equivalents of $\mathrm{NaIO}_{4}[11,13,19]$.

\subsection{Anti-Wrinkle Finishing Process Optimized by Response Surface Methodology (RSM)}

In order to determine the optimum anti-crease technological conditions for oxyRafinished cotton fabric with the pad-dry-cure method, the effects of magnesium chloride concentration, $\mathrm{pH}$ value, curing temperature and curing time on the anti-crease property were measured through a RSM central composite Box-Behnken Design (BBD) [20,21]. A response surface model (RSM) with four factors and three levels was designed using the Design Expert 11.0 software (Apple Computer Inc., Cupertino, CA, USA) and the levels of each factor are shown in Table 1. According to the 29 sets of test process parameters, the cotton fabric was finished with oxyRa. The results are recorded in Table 2, and regression analysis was performed on the data obtained.

WRA was selected as the response value, and the multiple regression analysis was performed according to the response surface test results, and the quaternary quadratic regression equation of WRA and catalyst concentration $\left(X_{1}\right), \mathrm{pH}$ value $\left(X_{2}\right)$, curing temperature $\left(\mathrm{X}_{3}\right)$, and curing time $\left(\mathrm{X}_{4}\right)$ was obtained as follows: $\mathrm{Y}=260.13+20.39 \mathrm{X}_{1}-2.99 \mathrm{X}_{2}-$ $2.04 \mathrm{X}_{3}-3.41 \mathrm{X}_{4}-5.78 \mathrm{X}_{1} \mathrm{X}_{2}+3.37 \mathrm{X}_{1} \mathrm{X}_{3}+0.47 \mathrm{X}_{1} \mathrm{X}_{4}-2.27 \mathrm{X}_{2} \mathrm{X}_{3}+0.82 \mathrm{X}_{2} \mathrm{X}_{4}+3.86 \mathrm{X}_{3} \mathrm{X}_{4}-$ 
$25.00 \mathrm{X}_{1}{ }^{2}-7.07 \mathrm{X}_{2}{ }^{2}-14.99 \mathrm{X}_{3}{ }^{2}-3.89 \mathrm{X}_{4}{ }^{2}$. The analysis of variance and significance of the overall model are shown in Table 3.

Table 1. Factors, design codes and levels of the BBD.

\begin{tabular}{ccccc}
\hline \multirow{2}{*}{ Factor } & Design Code & \multicolumn{3}{c}{ Design Level } \\
\cline { 3 - 5 } & & $\mathbf{- 1}$ & $\mathbf{0}$ & $\mathbf{+ 1}$ \\
\hline $\mathrm{MgCl}_{2}(\mathrm{~g} / \mathrm{L})$ & $\mathrm{X}_{1}$ & 16 & 20 & 24 \\
$\mathrm{pH}$ & $\mathrm{X}_{2}$ & 3 & 4 & 5 \\
Curing Temperature $\left({ }^{\circ} \mathrm{C}\right)$ & $\mathrm{X}_{3}$ & 150 & 160 & 170 \\
Curing Time $(\mathrm{s})$ & $\mathrm{X}_{4}$ & 120 & 150 & 180 \\
\hline
\end{tabular}

Table 2. Experimental design and results of the BBD.

\begin{tabular}{cccccccc}
\hline Samples & $\mathbf{X}_{\mathbf{1}}$ & $\mathbf{X}_{\mathbf{2}}$ & $\mathbf{X}_{\mathbf{3}}$ & $\mathbf{X}_{\mathbf{4}}$ & $\left.\mathbf{W R A} \mathbf{( f}+\mathbf{w}) \mathbf{(}^{\circ}\right)$ & $\mathbf{T S} \mathbf{( \% )}$ & $\mathbf{W I}$ \\
\hline 1 & 20 & 4 & 170 & 120 & 240.33 & 63.3 & 58.11 \\
2 & 24 & 4 & 150 & 150 & 239.00 & 74.4 & 69.78 \\
3 & 20 & 4 & 150 & 120 & 250.87 & 79.1 & 72.29 \\
4 & 16 & 3 & 160 & 150 & 202.07 & 60.1 & 67.21 \\
5 & 20 & 4 & 160 & 150 & 261.09 & 73.7 & 67.24 \\
6 & 16 & 4 & 150 & 150 & 215.32 & 76.8 & 74.07 \\
7 & 20 & 5 & 170 & 150 & 227.80 & 61.9 & 61.96 \\
8 & 16 & 5 & 160 & 150 & 206.43 & 73.9 & 68.12 \\
9 & 20 & 4 & 160 & 150 & 259.49 & 74.1 & 67.61 \\
10 & 20 & 5 & 150 & 150 & 232.70 & 73.6 & 72.71 \\
11 & 20 & 4 & 160 & 150 & 259.49 & 74.1 & 67.61 \\
12 & 20 & 4 & 150 & 180 & 234.22 & 68.5 & 69.40 \\
13 & 20 & 3 & 150 & 150 & 239.11 & 69.0 & 67.81 \\
14 & 20 & 4 & 170 & 180 & 239.11 & 69.3 & 67.83 \\
15 & 20 & 4 & 160 & 150 & 259.49 & 74.1 & 67.61 \\
16 & 20 & 3 & 160 & 180 & 246.42 & 63.5 & 68.47 \\
17 & 24 & 4 & 160 & 180 & 250.10 & 73.6 & 67.02 \\
18 & 24 & 3 & 160 & 150 & 261.18 & 71.4 & 67.88 \\
19 & 16 & 4 & 160 & 120 & 208.62 & 74.1 & 69.29 \\
20 & 24 & 5 & 160 & 150 & 242.07 & 73.7 & 68.22 \\
21 & 24 & 4 & 160 & 120 & 252.22 & 71.2 & 68.08 \\
22 & 20 & 5 & 160 & 180 & 248.44 & 73.6 & 65.02 \\
23 & 20 & 3 & 170 & 150 & 243.28 & 62.5 & 60.12 \\
24 & 24 & 4 & 170 & 150 & 236.66 & 63.1 & 64.31 \\
25 & 20 & 5 & 160 & 120 & 255.26 & 75.5 & 67.71 \\
26 & 20 & 3 & 160 & 120 & 256.50 & 70.5 & 68.75 \\
27 & 16 & 4 & 170 & 150 & 199.51 & 65.3 & 63.43 \\
28 & 20 & 4 & 160 & 150 & 261.09 & 73.7 & 67.24 \\
29 & 16 & 4 & 160 & 180 & 204.61 & 69.9 & 62.69 \\
\hline & & & & & & \\
\end{tabular}

From Table 3, the F value of the regression model is 26.54 , and the $p$ value was less than 0.0001 , indicating that the quadratic model which used in the experiment was very significant. $p$ value of $X_{1}, X_{1}{ }^{2}$ and $X_{3}{ }^{2}$ were all less than 0.0001 , indicating that their influence on the WRA was an extremely significant. $p$ value of $X_{4}$ and $X_{2}{ }^{2}$ was less than 0.05 , indicating that they have a significant effect on the WRA, while the $p$ values of $X_{2}$, $X_{3}$, and $X_{4}{ }^{2}$ were all greater than 0.05 , that was, there was a small significant effect on the WRA. $p$ values of the interaction items $\left(X_{1} X_{2}, X_{1} X_{3}, X_{1} X_{4}, X_{2} X_{3}, X_{2} X_{4}\right.$, and $\left.X_{3} X_{4}\right)$ were all greater than 0.05 , indicating that the interaction item has no significant effect on WRA, which means that the relationship between four factors and the WRA was not a simple linear relationship. Therefore, according to the influence on the WRA, the order of the four factors from high to low was: $X_{1}>X_{4}>X_{2}>X_{3}$. 
Table 3. ANOVA table for WRA.

\begin{tabular}{cccccc}
\hline Source & $\begin{array}{c}\text { Sum of } \\
\text { Squares }\end{array}$ & df & $\begin{array}{c}\text { Mean } \\
\text { Square }\end{array}$ & $\begin{array}{c}\text { F } \\
\text { Value }\end{array}$ & $\begin{array}{c}p \text {-Value } \\
\text { Prob }>\text { F }\end{array}$ \\
\hline Model & 10363.90 & 14 & 740.28 & 26.54 & $<0.0001$ \\
$\mathrm{X}_{1}$ & 4988.62 & 1 & 4988.62 & 178.83 & $<0.0001$ \\
$\mathrm{X}_{2}$ & 107.16 & 1 & 107.16 & 3.84 & 0.0702 \\
$\mathrm{X}_{3}$ & 50.14 & 1 & 50.14 & 1.80 & 0.2014 \\
$\mathrm{X}_{4}$ & 139.40 & 1 & 139.40 & 5.00 & 0.0422 \\
$\mathrm{X}_{1} \mathrm{X}_{2}$ & 137.71 & 1 & 137.71 & 4.94 & 0.0433 \\
$\mathrm{X}_{1} \mathrm{X}_{3}$ & 45.36 & 1 & 45.36 & 1.63 & 0.2230 \\
$\mathrm{X}_{1} \mathrm{X}_{4}$ & 0.89 & 1 & 0.89 & 0.032 & 0.8606 \\
$\mathrm{X}_{2} \mathrm{X}_{3}$ & 20.57 & 1 & 20.57 & 0.74 & 0.4050 \\
$\mathrm{X}_{2} \mathrm{X}_{4}$ & 2.66 & 1 & 2.66 & 0.095 & 0.7622 \\
$\mathrm{X}_{3} \mathrm{X}_{4}$ & 59.52 & 1 & 59.52 & 2.13 & 0.1662 \\
$\mathrm{X}_{1}^{2}$ & 4054.32 & 1 & 4054.32 & 145.33 & $<0.0001$ \\
$\mathrm{X}_{2}{ }^{2}$ & 323.96 & 1 & 323.96 & 11.61 & 0.0042 \\
$\mathrm{X}_{3}^{2}$ & 1456.70 & 1 & 1456.70 & 52.22 & $<0.0001$ \\
$\mathrm{X}_{4}^{2}$ & 98.01 & 1 & 98.01 & 3.51 & 0.0819 \\
Residual & 390.55 & 14 & 27.90 & & \\
Lack of Fit & 387.48 & 10 & 38.75 & 50.45 & 0.0009 \\
Pure Error & 3.07 & 4 & 0.77 & & \\
Cor Total & 10754.46 & 28 & & & Adeq Precision $=17.319$ \\
\hline $\mathrm{R}^{2}=0.9637$ & \multicolumn{2}{c}{$\mathrm{R}_{\mathrm{adj}}{ }^{2}=0.9274$} & & \\
\hline
\end{tabular}

The lack of fit can indicate the difference between the model and the results, the $p$ value of the model's lack-of-fit item is 0.051 , satisfying the condition of being greater than 0.05 , and indicating that the lack of fit item is not significant and there is no lack of fit factor. It also proves that the equation can be used to predict the WRA and analyze the anti-wrinkle property of the finished fabric. When the coefficient of determination $\left(R^{2}\right)$ is close to 1 , means that higher the fit and more practical of this model. The $\mathrm{R}^{2}$ of the model is 0.9560 , indicating that the fit is good and can be used to predict the WRA of the fabric. The corrected coefficient of determination $\left(\mathrm{R}_{\mathrm{adj}}{ }^{2}\right)$ is 0.9121 , which means that the model can predict $91.21 \%$ of the response value change.

According to the obtained quaternary quadratic regression equation, WRA's 3D response surface plots of the four factors were made by Design Expert 11.0, and the result is shown in Figure 4. The Figure 4a-f respectively show the WRA's dynamic changes of the four influencing factors in the process of finishing cotton fabric with oxyRa finishing agent, and the optimal value range of each factor. The slope of the curved surface can reflect the influence of two factors on the response value, the smoother the slope of the curved surface was mean that the interaction of the two factors had less influence on the WRA, while the slope was steeper, the opposite was true. The shape of the contour line in the figure can also indicated the strength of the interaction between the two influencing factors. If the contour line was elliptical, it means that the interaction between the two factors is strong, and if the contour line was circular, it means the interaction between the two factors was not significant.

From the six response surface Figure $4 \mathrm{a}-\mathrm{f}$, the interactions between the concentration of $\mathrm{MgCl}_{2}$ and $\mathrm{pH}$ value, curing temperature, and curing time were relatively strong, and the effect on the WRA was more significant. As the concentration of $\mathrm{MgCl}_{2}$ was increased from 16 to $24 \mathrm{~g} / \mathrm{L}$, the change of WRA increases at the beginning stage and then decreases, indicated that excessive $\mathrm{MgCl}_{2}$ cannot keep WRA increasing. When the amount of catalyst was $20 \mathrm{~g} / \mathrm{L}$, the WRA of treated fabric was the maximum. This was because the crosslinking reaction between the oxyRa and cotton cellulose may be achieved under the action of a certain $\mathrm{pH}$ and catalyst and a certain curing time and temperature. In contrast, the interaction between $\mathrm{pH}$ and curing temperature, curing time, and the interaction between curing temperature and curing time has little effect on the WRA. 
(a)

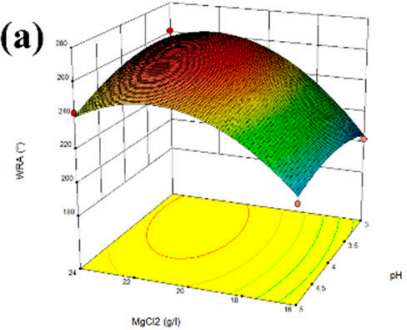

(d)

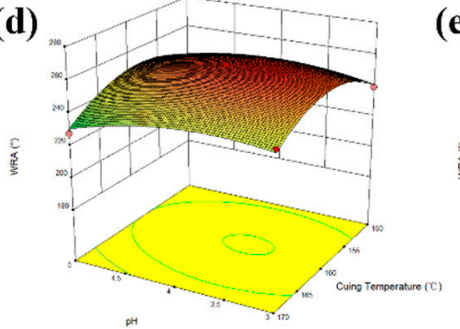

(b)

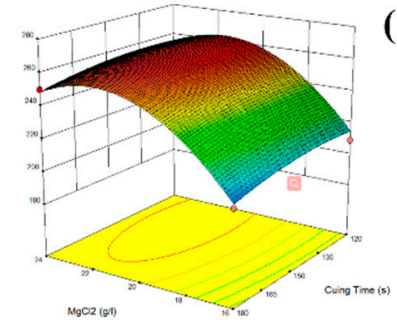

(e)

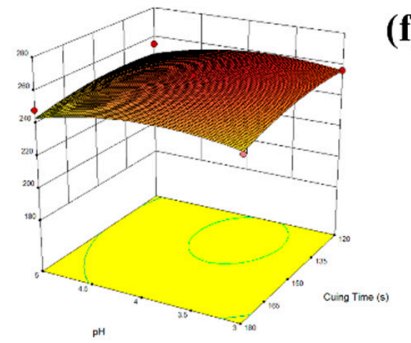

(c)

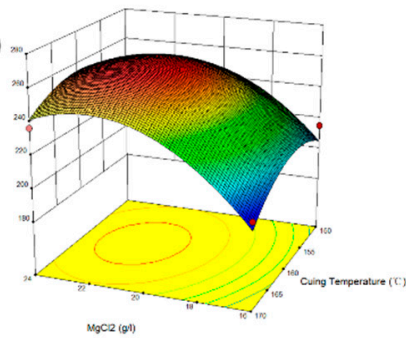

(f)

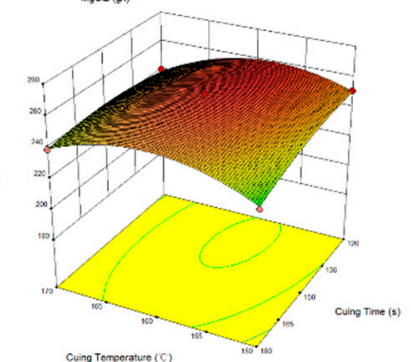

Figure 4. 3D surface plot for WRA with 4 factors. ((a) is WRA's dynamic changes of the $\mathrm{MgCl}_{2}$ and $\mathrm{pH}$, (b) is WRA's dynamic changes of the $\mathrm{MgCl}_{2}$ and Curing Time, (c) is WRA's dynamic changes of the $\mathrm{MgCl}_{2}$ and Curing Temperature, (d) is WRA's dynamic changes of the $\mathrm{pH}$ and Curing Temperature, (e) is WRA's dynamic changes of the $\mathrm{pH}$ and Curing Time, (f) is WRA's dynamic changes of the Curing Temperature and Curing Time).

In Figure 4, the model's prediction of the optimal finishing process of WRA was the catalyst concentration was $20.12 \mathrm{~g} / \mathrm{L}$, $\mathrm{pH}$ was 4.32 , curing temperature was $150^{\circ} \mathrm{C}$ and curing time was $120 \mathrm{~s}$. Under this condition, the predicted WRA of the finished fabric was up to $249.76^{\circ}$, TS was $75.62 \%$, WI was 70.69 (ANOVA table for TS and WI were shown in the experimental supplementary files.). According to this process parameter, we conducted three sets of repeated experiments to verify the correctness of the prediction process. The obtained WRA was $245.23^{\circ}$, TS was $71.13 \%$, and WI was 68.11 , these experimental results were similar to the predicted results, indicated that the regression model can effectively predict the anti-wrinkle performance of oxyRa finished fabrics, and also verified the reliability of the fabric anti-wrinkle finishing model established by RSM.

\subsection{Anti-Wrinkle Finishing and Dyeing of the Fabrics}

The anti-wrinkle and dyeing properties of fabrics treated with oxyRa, DMDHEU, glutaraldehyde, and BTCA with the pad-dry-cure method were summarized in Table 4. No. 1, 3, 6, 9, 12 were the fabrics with anti-wrinkle finishing only. No. 2 was the fabric with dyeing only. No. 4, 7, 10, 13 were the fabrics with dyeing, and then with antiwrinkle finishing. No. 5, 8, 11, 14 were the fabrics with anti-wrinkle finishing, and then with dyeing.

From No. 1 and 3 in Table 4, it was evident that the WRA of the oxyRa-treated fabric were obviously better than reference, being $245.23^{\circ}$, a $106.87 \%$ increase over the control. This was equivalent to DMDHU-treated fabrics $\left(247.25^{\circ}\right)$, much lower than WRA of GAand BTCA-treated fabric $\left(251.21^{\circ}\right.$ and $\left.262.64^{\circ}\right)$, which indicated that oxyRa can cross-link with the cotton fabric to impart anti-wrinkle properties to the fabric. This was because the aldehyde groups of oxyRa were combined with the hydroxyl groups of cotton cellulose to form hemiacetals or acetals, and a network structure was formed inside the fiber to reduce the relative slippage between the cellulose $[12,22,23]$, thereby improving the anti-wrinkle properties of the fabric.

No. 4, 7, 10, 13 were the fabrics with dyeing, and then with anti-wrinkle finishing, the anti-wrinkle performance of the finished fabric was obviously decreased compared with No. 2, and the color of the fabrics were deepened, and the $\mathrm{k} / \mathrm{s}$ value increased. It can also be seen from Figure 5 that the apparent color of the fabric becomes darker. This shows the defect of the processing technology of dyeing first and then finishing, and it was also the reason we designed the anti-wrinkle first and then dye process. 
Table 4. Properties of fabrics treated with oxyRa, DMDHEU, GA and BTCA.

\begin{tabular}{|c|c|c|c|c|c|c|c|c|}
\hline No. & Samples & $\begin{array}{c}\text { Curing } \\
\text { Temperature }\left({ }^{\circ} \mathrm{C}\right)\end{array}$ & $\begin{array}{l}\text { Curing } \\
\text { Time (s) }\end{array}$ & WRA $\left(^{\circ}\right)$ & TS (\%) & WI & $\mathrm{k} / \mathrm{s}$ & $\Delta \mathrm{E}$ \\
\hline 1 & Reference & 150 & 120 & 118.54 & 100.00 & 83.15 & / & / \\
\hline 2 & Reference-1 & 150 & 120 & 129.35 & 98.50 & / & 19.63 & 0 \\
\hline 3 & $\mathrm{OxyRa}^{\mathrm{a}}$ & 150 & 120 & 245.23 & 64.90 & 62.35 & / & / \\
\hline 4 & OxyRa-1 ${ }^{\text {a }}$ & 150 & 120 & 207.15 & 60.01 & / & 24.02 & 2.43 \\
\hline 5 & OxyRa-2 a & 150 & 120 & 238.43 & 58.07 & / & 13.88 & 3.49 \\
\hline 6 & DMDHEU a & 160 & 120 & 247.25 & 65.82 & 68.42 & / & / \\
\hline 7 & DMDHEU-1 ${ }^{\text {a }}$ & 160 & 120 & 219.74 & 60.07 & / & 24.39 & 1.96 \\
\hline 8 & DMDHEU-2 ${ }^{a}$ & 160 & 120 & 230.32 & 61.73 & / & 6.91 & 8.46 \\
\hline 9 & $\mathrm{GA}^{\mathrm{a}}$ & 150 & 120 & 251.21 & 64.54 & 71.84 & / & / \\
\hline 10 & GA-1 ${ }^{a}$ & 150 & 120 & 212.53 & 66.40 & / & 20.17 & 0.43 \\
\hline 11 & GA-2 ${ }^{a}$ & 150 & 120 & 229.42 & 65.93 & / & 8.02 & 7.29 \\
\hline 12 & BTCA $^{b}$ & 180 & 120 & 262.64 & 58.88 & 68.13 & / & / \\
\hline 13 & BTCA-1 ${ }^{b}$ & 180 & 120 & 211.85 & 54.73 & / & 23.52 & 1.99 \\
\hline 14 & BTCA-2 ${ }^{b}$ & 180 & 120 & 229.16 & 53.89 & / & 1.78 & 16.40 \\
\hline
\end{tabular}

${ }^{\mathrm{a}}$ used $20.12 \mathrm{~g} / 1 \mathrm{MgCl}_{2} \cdot 6 \mathrm{H}_{2} \mathrm{O}$ as the catalyst, and ${ }^{\mathrm{b}}$ used $20.12 \mathrm{~g} / \mathrm{L} \mathrm{NaH}_{2} \mathrm{PO}_{2} \cdot \mathrm{H}_{2} \mathrm{O}$ as the catalyst. The $\mathrm{pH}$ of all finishing agents was 4.32 .
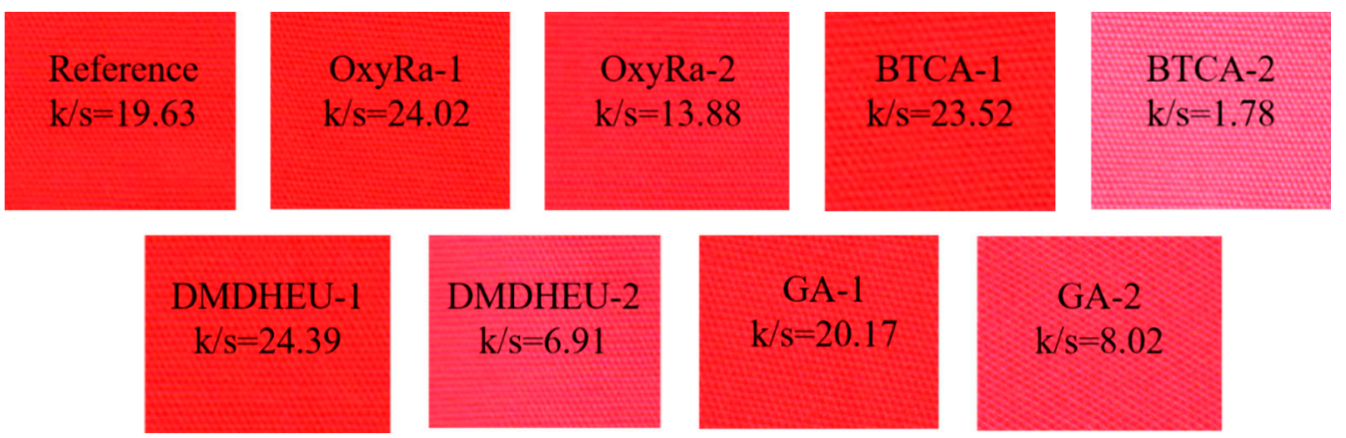

Figure 5. K/S and apparent color of treated fabrics.

From No. 5, 8, 11, 14, after anti-wrinkle finishing and dyeing finishing, the difference in WRA of the four fabrics were small, but the $\mathrm{k} / \mathrm{s}$ value of the fabrics dyed after oxyRa finishing was 13.88, which was significantly higher than that of the fabrics finished with DMDHEI, GA and BTCA, and the $\triangle \mathrm{E}$ value was the smallest. This means that after the fabric was finished with oxyRa, the color of the fabric was deeper and closer to the reference (No. 2). From Figure 5, the apparent color of the No. 5 sample was also deeper than No. 8, 11 , and 14, indicating that the hydrophilicity of the fabric after DMDHEU, GA and BTCA finishing was decreased, and it was not easy to combined dyes, which made the fabric difficult to dye. It was because that there were covalent binding reactions between the crosslinking agents and the hydroxyl groups of the fibers during the finishing process, in which some of the hydroxyl groups reacted, so the number of hydroxyl groups that can form hydrogen bonds with the dye was decreased. This can be further analyzed from the combination mechanism of reactive dye, crosslinkers and fibers in Scheme 2.

It would be interesting to understand the mechanism of the reactive dye and four crosslinking agents with cotton cellulose, and analyze the effects of changes in hydroxyl contents in the finishing and dyeing process (Figure 4a-e) $[13,17,18]$. From the combination mechanism that dyeing and anti-wrinkle finishing agents have a competitive relationship with the hydroxyl groups of cellulose, and the hydroxyl content of cellulose was reduced after the combination [24-27]. In Figure 4a, the reactive groups (halogen atom-chlorine) of the reactive dye undergoes the covalent bonding reaction with the hydroxyl groups of the cellulose, which reduces the hydroxyl content of the fiber. In the reaction of oxyRa with the cellulose hydroxyl group (Figure $4 b$ ), the hydroxyl group itself was introduced into the fiber chain. Thus, the number of hydroxyl groups in the treated fabric did not 
decrease significantly, the key to be able to apply the anti-wrinkle finishing to the fabric before the dyeing process. After DMDHEU, GA and BTCA were combined with cellulose, the number of hydroxyl groups consumed was more than that of the hydrophilic groups introduced with the molecule, resulting in serious decrease in hydrophilicity and poor color staining of the fabric. Therefore, their dyeability was in order of high to low: oxyRa > BTCA > DMDHEU > GA.

(a)<smiles>OSSSO</smiles>

Cellulose

(b)

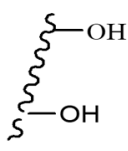

Cellulose

(c)

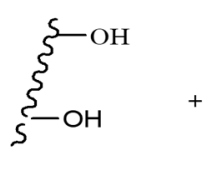

(d)

Cellulose<smiles>OSSSS</smiles>

(e)

Cellulose<smiles>OSSSO</smiles>

Cellulose<smiles>ONc1nc(Cl)nc(Cl)n1</smiles>

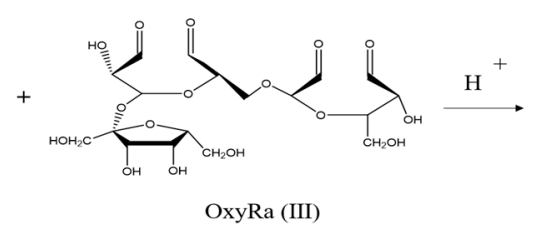

OxyRa (III)<smiles>O=CCCCC=O</smiles>

GA

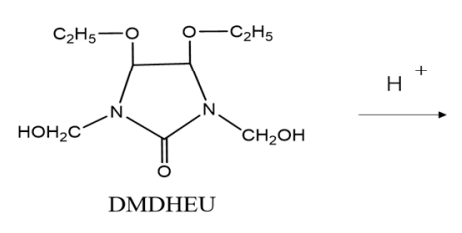

-

BTCA

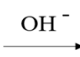

$\mathrm{H}^{+}$

$\mathrm{H}^{+}$
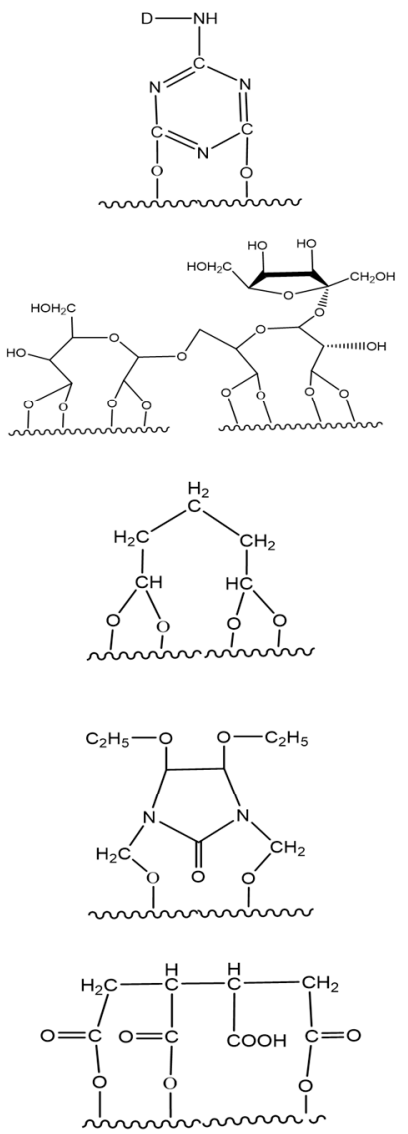

Scheme 2. Reaction mechanism of the reactive dye and four crosslinking agents with cellulose. ((a) was the reaction mechanism of the reactive dye EC-3GL, (b-e) was the reaction mechanism of OxyRa, Ga, DMDHEU and BTCA).

\section{Conclusions}

We successfully prepared a new type of anti-wrinkle finishing agent, which solved the problem of reduced dyeability of cotton fabric after anti-wrinkle finishing. Partially oxidized raffinose polyaldehyde derivatives (oxyRa) was prepared by oxidation with sodium periodate. FTIR and ${ }^{13} \mathrm{C}-\mathrm{NMR}$ proved that the molecular structure of oxyRa contained aldehyde groups, and the content of aldehyde groups was $17.54 \mathrm{mmol} / \mathrm{g}$. The optimal finishing process and the best finishing effect of oxyRa were predicted by the RSM, the correctness of the predicted results was verified through the corresponding experimental process, and oxyRa finished fabric has good WRA, ST, WI. In addition, the analysis of the $\mathrm{k} / \mathrm{s}$ value and the apparent color of the fabric after anti-wrinkle finishing with different finishing agents shows that the $\mathrm{k} / \mathrm{s}$ of the oxyRa-finished fabric was the highest, which was also the closest to the reference compared to DMDHEU, GA and BTCA. Anti-wrinkle property of oxyRa-treated fabrics was obtained by the reaction of an ether bond, formed by dehydration and condensation between the aldehyde group of oxyRa and the hydroxyl group of cellulose. The dying properties of oxyRa-finished fabric 
were improved because hydroxyl groups were added to raffinose while the hydroxyls of cellulose were consumed in the etherification reaction.

Author Contributions: Conceptualization, X.F. and J.Z.; Writing—original draft preparation, J.L.; Writing-review and editing, D.W. All authors have read and agreed to the published version of the manuscript.

Funding: This work was financially supported by the National Key R\&D Program of China (2017YFB0309202) and Postgraduate Research \& Practice Innovation Program of Jiangsu Provence (1062050205198056).

Institutional Review Board Statement: Not applicable.

Informed Consent Statement: Not applicable.

Conflicts of Interest: The authors declare no conflict of interest.

\section{References}

1. Dehabadi, V.A.; Buschmann, H.-J.; Gutmann, J.S. Durable press finishing of cotton fabrics: An overview. Text. Res. J. 2013, 83, 1974-1995. [CrossRef]

2. Harifi, T.; Montazer, M. Past, present and future prospects of cotton cross-linking: New insight into nano particles. Carbohydr. Polym. 2012, 88, 1125-1140. [CrossRef]

3. Chang, H.L.; Chen, C.C. Crosslinking of Cotton with DMDMDHEU in the Presence of Sodium Chloride. Text. Res. J. 2016, 66, 803-809. [CrossRef]

4. Ji, B.; Tang, P.; Yan, K.; Sun, G. Catalytic actions of alkaline salts in reactions between 1,2,3,4-butanetetracarboxylic acid and cellulose: II. Esterification. Carbohydr. Polym. 2015, 132, 228-236. [CrossRef]

5. He, X.; Tao, R.; Zhou, T.; Wang, C.; Xie, K. Structure and properties of cotton fabrics treated with functionalized dialdehyde chitosan. Carbohydr. Polym. 2014, 103, 558-565. [CrossRef] [PubMed]

6. Ji, B.; Tang, P.; Hu, C.; Yan, K. Catalytic and ionic cross-linking actions of l-glutamate salt for the modification of cellulose by 1,2,3,4-butanetetracarboxylic acid. Carbohydr. Polym. 2019, 207, 288-296. [CrossRef] [PubMed]

7. Wang, H.; Zhang, C.; Chu, X.; Zhu, P. Mechanism of Antiwrinkle Finishing of Cotton Fabrics Using Mixed Polycarboxylic Acids. Int. J. Polym. Sci. 2020, 2020, 3876595. [CrossRef]

8. Zhang, X.; Ji, B.; Yan, K.; Hu, T. Non-phosphorus catalysts for the ester cross-linking of cellulose with 1,2,3,4-butanetetracarboxylic acid. Fibers Polym. 2017, 18, 682-688. [CrossRef]

9. Monier, M.; El-Sokkary, A.M. Modification and characterization of cellulosic cotton fibers for efficient immobilization of urease. Int. J. Biol. Macromol. 2012, 51, 18-24. [CrossRef] [PubMed]

10. Tang, P.; Ji, B.; Sun, G. Whiteness improvement of citric acid crosslinked cotton fabrics: $\mathrm{H}_{2} \mathrm{O}_{2}$ bleaching under alkaline condition. Carbohydr. Polym. 2016, 147, 139-145. [CrossRef] [PubMed]

11. Wang, P.; Sheng, F.; Tang, S.W.; ud-Din, Z.; Chen, L.; Nawaz, A.; Hu, C.; Xiong, H. Synthesis and Characterization of Corn Starch Crosslinked with Oxidized Sucrose. Starch-Stärke 2018. [CrossRef]

12. Dang, X.; Liu, P.; Yang, M.; Deng, H.; Shan, Z.; Zhen, W. Production and characterization of dialdehyde cellulose through green and sustainable approach. Cellulose 2019, 26, 9503-9515. [CrossRef]

13. Liu, P.; Xu, H.; Mi, X.; Xu, L.; Yang, Y. Oxidized Sucrose: A Potent and Biocompatible Crosslinker for Three-Dimensional Fibrous Protein Scaffolds. Macromol. Mater. Eng. 2015, 300, 414-422. [CrossRef]

14. Muhammad, M.; Willems, C.; Rodriguez-Fernandez, J.; Gallego-Ferrer, G.; Groth, T. Synthesis and Characterization of Oxidized Polysaccharides for In Situ Forming Hydrogels. Biomolecules 2020, 10, 1185. [CrossRef] [PubMed]

15. Munster, L.; Vicha, J.; Klofac, J.; Masar, M.; Hurajova, A.; Kuritka, I. Dialdehyde cellulose crosslinked poly(vinyl alcohol) hydrogels: Influence of catalyst and crosslinker shelf life. Carbohydr. Polym. 2018, 198, 181-190. [CrossRef] [PubMed]

16. Ibrahim, N.A.; Amr, A.; Eid, B.M.; Almetwally, A.A.; Mourad, M.M. Functional finishes of stretch cotton fabrics. Carbohydr. Polym. 2013, 98, 1603-1609. [CrossRef] [PubMed]

17. Pourjavadi, A.; Aghajani, V.; Ghasemzadeh, H. Synthesis, characterization and swelling behavior of chitosan-sucrose as a novel full-polysaccharide superabsorbent hydrogel. J. Appl. Polym. Sci. 2008, 109, 2648-2655. [CrossRef]

18. Yue, H.; Zheng, Y.; Zheng, P.; Guo, J.; Fernández-Blázquez, J.P.; Clark, J.H.; Cui, Y. On the improvement of properties of bioplastic composites derived from wasted cottonseed protein by rational cross-linking and natural fiber reinforcement. Green Chem. 2020, 22, 8642-8655. [CrossRef]

19. Du Penhoat, C.H.; Engelsen, S.B.; Plusquellec, D.; Perez, S. A structural study of 2-O-lauroylsucrose with molecular modeling and NMR methods. Carbohydr. Res. 1997, 305, 131-145. [CrossRef]

20. Aleboyeh, A.; Daneshvar, N.; Kasiri, M.B. Optimization of C.I. Acid Red 14 azo dye removal by electrocoagulation batch process with response surface methodology. Chem. Eng. Process. Process Intensif. 2008, 47, 827-832. [CrossRef] 
21. Ghodsiyeh, D.; Golshan, A.; Hosseininezhad, N.; Hashemzadeh, M.; Ghodsiyeh, S. Optimizing Finishing process in WEDMing of Titanium Alloy (Ti6Al4V) by Zinc Coated Brass Wire based on Response Surface Methodology. Indian J. Sci. Technol. 2012, 5, 3365-3377. [CrossRef]

22. Balakrishnan, P.; Geethamma, V.G.; Gopi, S.; Thomas, M.G.; Kunaver, M.; Huskic, M.; Kalarikkal, N.; Volova, T.; Rouxel, D.; Thomas, S. Thermal, biodegradation and theoretical perspectives on nanoscale confinement in starch/cellulose nanocomposite modified via green crosslinker. Int. J. Biol. Macromol. 2019, 134, 781-790. [CrossRef]

23. Madan, G.L.; Patel, S.B.; Baddi, N.T. Physical Chemistry of Crosslinking. Text. Res. J. 2016, 46, 329-342. [CrossRef]

24. Bhatti, I.A.; Adeel, S.; Fazal ur, R.; Irshad, M.; Abbas, M. Effect of mercerization and gamma irradiation on the dyeing behaviour of cotton using stilbene based direct dye. Radiat. Phys. Chem. 2012, 81, 823-826. [CrossRef]

25. Gam, D.H.; Hong, J.W.; Kim, J.H.; Kim, J.W. Skin-Whitening and Anti-Wrinkle Effects of Bioactive Compounds Isolated from Peanut Shell Using Ultrasound-Assisted Extraction. Molecules 2021, 26, 1231. [CrossRef] [PubMed]

26. Lu, Z.; Huang, J.; Li, J.; Si, L.; Yao, C.; Jia, F.; Zhang, M. All cellulose composites prepared by hydroxyethyl cellulose and cellulose nanocrystals through the crosslink of polyisocyanate. Carbohydr. Polym. 2020, 250, 116919. [CrossRef] [PubMed]

27. Luo, X.; Shao, D.; Wang, X.; Xu, C.; Gao, W. Whitening citric acid treated cotton fabrics by a TBCC-activated peroxide postbleaching. Cellulose 2020, 27, 5367-5376. [CrossRef] 